\title{
Could Business Organizations Simulate the Brain's Implicit Learning Process? And Apply That to Strategic Thinking?
}

\author{
M S S El Namaki
}

\section{VU School of Management, Switzerland}

\begin{abstract}
This paper draws the parallel between the processes of learning in the human brain with strategic thinking in business organisations. It also suggests implicit learning as a possible element within the cognitive functions of artificial intelligence. Five case examples are provided to illustrate innovative strategic thinking with the use of Big Data.
\end{abstract}

Keywords: Big Data, Artificial Intelligence, Strategic Thinking, Implicit Learning 


\section{The Problem}

The human brain learns. And it does that in many ways. Cognition, sensing, and memory play a key role in the process. Human memory could be either long-term or short-term, with the long-term memory having an implicit or explicit dimension. The former one is associated with unconscious memory, also known as automatic memory. Implicit long term memory performs "implicit learning" a form of learning that occurs without the individual's awareness as it evolves from continuous exposure to events and stimuli (Curran and Schacter, 2001), and relies on "non-explicit" mechanisms of the brain (Muraskin et al., 2016).

Could a similar process emerge in business organizations? Could business organizations develop an ability to learn implicitly and derive creative strategies form this implicit learning? Could Artificial Intelligence support this process? This will be the focus of the following article.

The article starts with an analysis of the process of learning in the human brain. It further explores the brain specific non-conventional or implicit, approach to learning and how that delivers creative solutions. The article further draws a parallel scenario for business organizations. The article explores the possible introduction of implicit learning systems within business organizations, including systems that simulate the human brain's implicit learning and implicit memory construct, as well as a system that would enhance strategic thinking within those organizations. It also suggests implicit learning as a possible element within the cognitive functions of artificial intelligence.

\section{What is learning?}

Learning is about acquiring knowledge or skills via studying or experimentation and is a longitudinal process. It is often defined as a relatively lasting change in behaviour that is the result of experience (Curran and Schacter, 2001). Learning is an ongoing process that takes place throughout one's life. It may occur as part of education, personal development or any other informal or formal training process. It is also a continuous life-long process. Individuals constantly learn, unlearn and relearn through experiences in order to express ideas, to inform people, to communicate, to create and a myriad of other activities (Gross, 2014).

\subsection{What is implicit learning?}

Learning is a key cognitive function of the human brain. It is a process of acquiring or modifying knowledge, behaviours, skills, values, or preferences (Curran and Schacter, 2001; Gross, 2014; Xie et al., 2019). Learning takes place when neurons transmit sensory information through synapses and store it temporarily in a volatile region of the brain: the short-term memory. Once information processed it goes via neural pathways to the long-term memory. A comparison with existing memories follows and storage in the long-term memory ensues (Curran and Schacter, 2001; Pavlik and Anderson, 2005; Xie et al., 2019).

International Journal of Management and Applied Research, 2020, Vol. 7, No. 1 
In reference to Curran and Schacter (2001: 7237), "Learning is the acquisition of new information that leads to lasting changes in behaviour, and memory reflects the storage and retrieval of learned information". In the case when new information contradicts the previously known facts or beliefs, this conflict is typically resolved via cognitive process, resulting in new information either being rejected or confirmed and stored for the later use.

Neurons, the prime building block of human brains, undergo change through "plasticity" (Pavlik and Anderson, 2005), which is a learning-rooted process of creating and strengthening some neurons and neuronal connections and weakening or eliminating others, depending on the type of learning that the brain goes through. It is a core, lifelong feature of the brain with long term learning having the most profound impact. Propensity to learn varies over time, however, according to the type of stimuli the brain is exposed to. It is grounded into experiences of early years when sounds and speech have stronger impact than later in life, when learning tend to be dominated by vocabulary acquisition and experimentation (Pavlik and Anderson, 2005; Winter et al., 2018; Ullman, 2004). Altogether, learning is about acquisition of new information or experience with some bits being forgotten, whereas most striking elements can be remembered for a long time.

\subsubsection{Implicit and explicit memory}

There are two main sub-categories of the long-term memory: the implicit memory and the explicit memory (Figure 1). They differ in terms of memory content, content retrieval mode and what part of the brain structure they make use of. Implicit memory is an unconscious memory that is acquired and put to use without awareness. It can affect thoughts and behaviours. Explicit memory is a conscious memory whose prime function is the intentional recollection of factual information as well as previous experiences and concepts (Curran and Schacter, 2001 Therefore, explicit memory is often referred to as declarative memory and being described as having episodic and semantic aspects (Xie et al., 2019).

Figure 1: Implicit and Explicit Memory

\section{Long Term Memory}

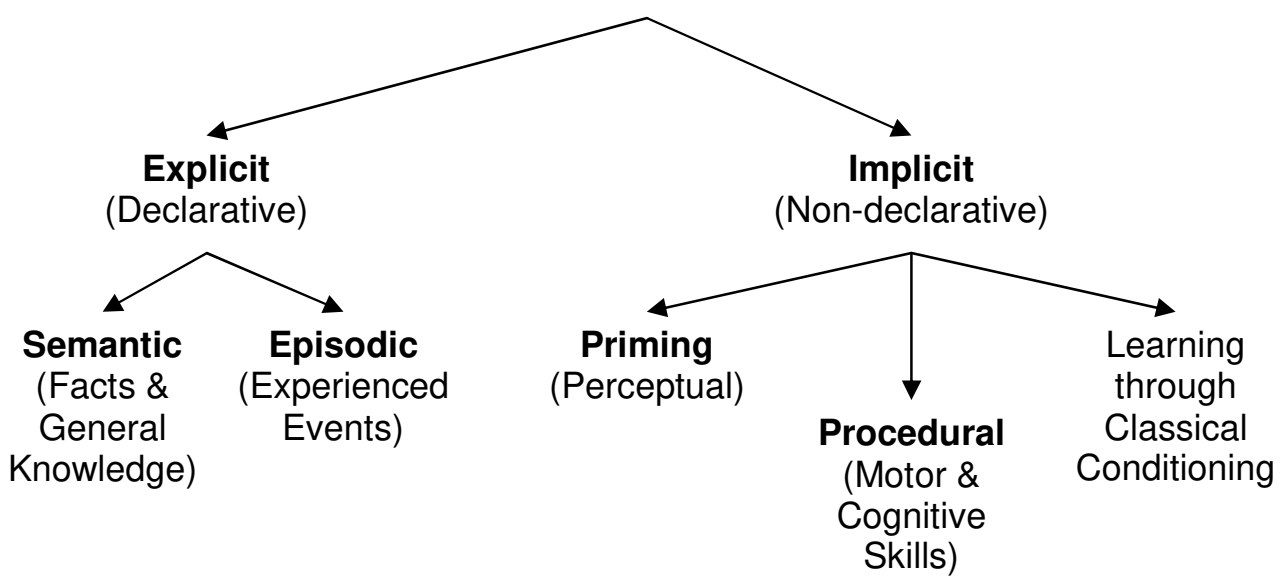

Adapted from: Stangor and Walinga (2014, p.366)

International Journal of Management and Applied Research, 2020, Vol. 7, No. 1 
Implicit memory has procedural and priming sub-sets, with the former one being helpful in performing usual tasks automatically that is guided previous experiences. Another smaller subset of implicit memory is priming or the act of associating stimuli to assist in recognizing an object or a concept. An example would be to think of the colour green to remember the word grass. We are "primed" by experiences (Curran and Schacter, 2001; Ullman, 2004; Xie et al., 2019).

\subsubsection{Explicit vs. implicit learning}

The brain engages in two types of learning: explicit and implicit. Explicit learning is learning that one has conscious awareness of and able to articulate what he or she learned (Schendan et al., 2003). Implicit learning is the opposite: it is the kind of learning that one has conscious access to, but cannot really articulate (Curran and Schacter, 2001).

Implicit learning relies on the two aspects of implicit memory: perceptual and conceptual priming. Perceptual priming refers to brain's ability to recognise stimuli, while conceptual priming is an ability to assess meaning of events and/or facts based on available semantic information (Curran and Schacter, 2001; Ullman, 2004; Xie et al., 2019). It is also linked to category and sequence learning (Schendan et al., 2003). In general, implicit learning relies on the brain's ability to engage its different regions based on the type of the processed information and it is modifiable via experience. Implicit learning's knowledge is also claimed to lie at the very core of creativity. Citing philosopher Michael Polanyi, Reber (2001: 15433) stated: "to engage in a creative act (is) to struggle to make tacitly acquired and held knowledge conscious and communicable".

\section{Could business organizations develop implicit learning competency?}

A business organization could find itself in an implicit learning situation when it uncovers objects, actions attributes or even strategies whose roots were hence unknown. Consequent analysis would reveal that those have emerged from an exposure to hence invisible stimuli. Stimuli originating from immediate or distant force fields within the organizations own periphery or within distant and unrelated arenas. "Silent signals" emitted from within those peripheries were sensed by the organizations receptors (Heilmann et al., 2020), information systems for example, disregarded but stored into the organizations implicit long term memory. An implicit learning exercise ensued when the organization sensed a need for a creative alternative to existing practices. It is a process that combines several competencies. Prime among those is data identification, access and assembly, data processing, data analysis, and last but not least, data derived learning. It is this data triggered analysis and learning that could create a state of implicit learning and induce a novel approach to strategic thinking.

Artificial Intelligence (AI) could provide a medium here. AI systems resort to data as an input and to learning as a transformation process. AI systems collect and are exposed to torrents of data. AI systems also conduct data analysis and learning along machine learning and deep learning constructs within system flows. AI supported organizations are more likely than not to enhance implicit memory (of the

International Journal of Management and Applied Research, 2020, Vol. 7, No. 1 
organization) by developing algorithms and sub technologies that are not immediately relevant to the organizations today's functions. Those are stored, then, in the organizations implicit memory and may become dormant or even unconscious until the day the organization faces silent signals from distant peripheries. Organizations resort to what is termed the "implicit knowledge management process" (Arena et al., 2018), a process that employs tools, techniques and methodologies that capture these previously elusive outcomes and processes and make them more generally available to the organization.

\section{Could the organizations' implicit learning competency boost strategic thinking?}

The answer is a hypothetically affirmative.

One could hypothesize that the potential for an impact is there. In very much the same way that the human brain resorts to implicit learning to enhance cognitive competencies, executives and corporation could resort to implicit learning to enhance the scope, depth and reach of strategic thinking. And in very much the same way that human brain enhancement of cognitive capacities comes through the growing of new neurons, executives and businesses could enhance their strategic thinking potential by enhancing their implicit memory construct. Implicit organization memory could be enhanced by greater exposure to silent signals and stimuli originating from beyond the organizations immediate periphery.

Systems theory can provide a framework for the process. There are inputs, transformations and outputs. Inputs are technology, market and industry data as well as silent signals. Transformation is the process of implicit learning. Outputs are novel and creative strategies as well as new products, services and sub systems. A feedback supplies corrective actions. The following figure illustrates this process.

Figure 2: Implicit learning system

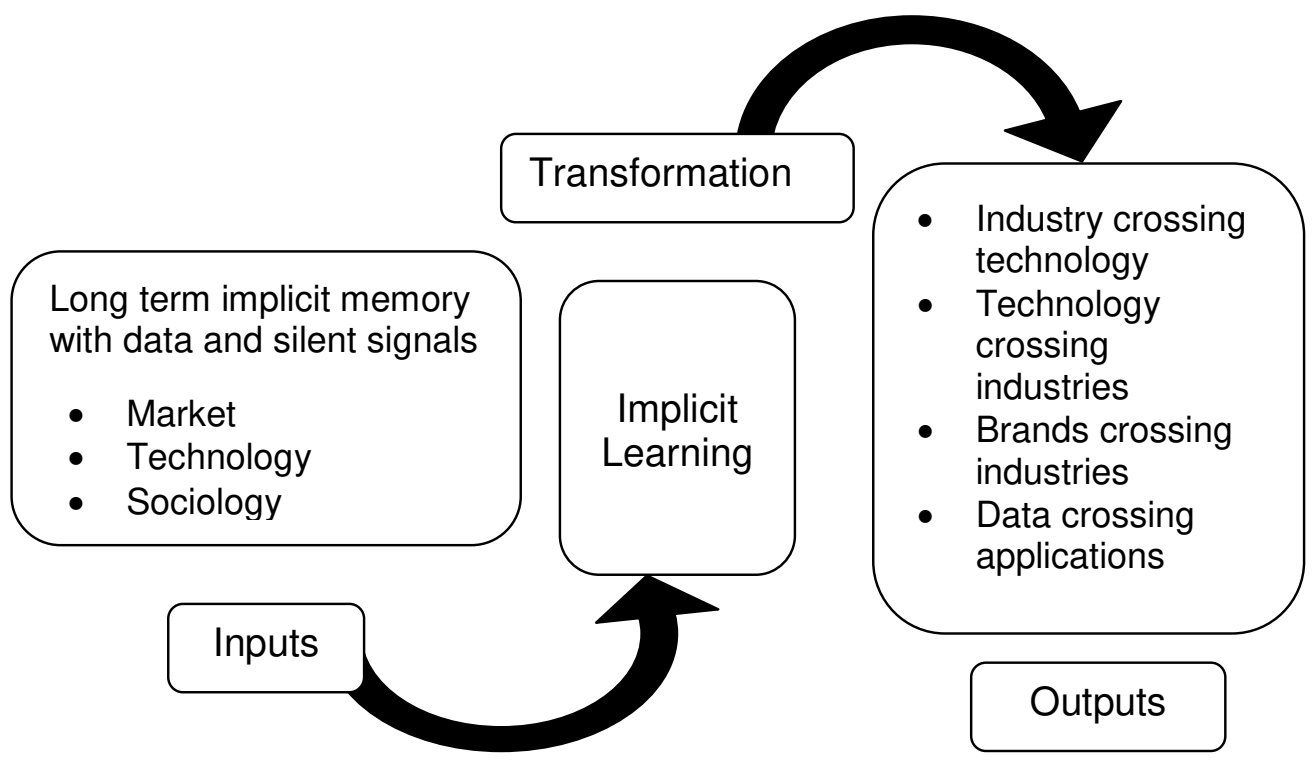

International Journal of Management and Applied Research, 2020, Vol. 7, No. 1 
This paradigm could have far reaching implications for strategic thinking. Conventional approaches to the concept rely, to a very large extent, on present day, and at times yesterday's, knowledge. Silent signals and stimuli do not seem to have a significant bearing on the strategic thinking process or the outcome of that process. Strategic moves seem to be incremental rather than "revolutionary"! One has only to follow Microsoft's windows software to identify evidence.

\section{Case evidence}

\subsection{Case one: Brands crossing industries}

Brands are cutting across industrial branches and markets reflecting an implicit learning process. Traditional brand strategy that created differentiation around a business model is giving way to novel business models making brands constantly relevant. The outcome is a type of compelling competition emerging from invisible corners, hidden from sight, impossible to predict, hard to pre-empt, and difficult to challenge (Brodie et al., 2017; Burmann et al., 2017; Castro and Giraldi, 2018). Take the case of Philips and Nike. Back in the 2000s, Philips and Nike once introduced a range of portable devices - such as radios, MP3 and CD players - designed specifically to be worn on the body during athletic activity (Viksnins, 2004). The alliance sought a function that goes beyond the music function of MP3 to wearable technology. This could see the applications of smart fabric for health monitoring (Aziz and Chang, 2018), such as incorporating GPS tracking systems in shoes (Yang and Kels, 2016).

\subsection{Case two: Businesses reinventing core competencies}

Businesses develop core competencies but these could mature and eventually die. Some seek an innovative extension of existing life or a new life altogether. Their search of an enhancement of existing core competency or the configuration of a new competency altogether could take them down the implicit learning route. They could "sense" market and technology shifts and implicit learning helps revealing new arenas and novel competencies. Cambridge Analytics and Facebook provide an example here. US Facebook users were subjected to media interventions during a presidential campaign with the ultimate aim of expressing preference to specific candidates. Millions of Facebook profiles of US voters were harvested and accessed in the process (Venturini and Rogers, 2019). A repeat performance was done in the Brexit campaign (Berghel, 2018). Facebook Analytics or the medium to "insights into business" followed and Facebook entered a new business arena.

\subsection{Case three: Data creating industries}

Big data is crossing industry boundaries and assuming the key role in new industry creation. It reflects the case when data is no longer serves its initial and somewhat limited purpose. Instead data is being aggregated and combined with a purposeful analysis towards innovative solutions and hence, it may create even new industries.

Consider the case of IBM and Twitter. IBM and Twitter have joined hands in order to sell analytical information to corporate clients. IBM analyzes Twitter's data and

International Journal of Management and Applied Research, 2020, Vol. 7, No. 1 
combines it with other public and business sources in order to help businesses "to tap into billions of real-time conversations to make smarter decisions", according to Glenn Finch, Global Leader Data and Analytics (Pham, 2015). This partnership rests on companies abilities to leverage their core competences: IBM utilises its analytical capacity, while Twitter aggregates large volumes of contextual data.

\subsection{Case four: Technology crossing industries}

Technology drives the continuous change of almost all industries. The music industry is not an exception to this rule. Terrestrial radio has been marginalised by the rise of streaming and digital distribution. The next level was the emergence of cloud based services and opportunities provided by Big Data analysis performed by artificial intelligence. In parallel to that, social media enabled the new ways of music personalisation and distribution (Maasø, 2018).

\section{Conclusion}

The human brain learns ubiquitously and it does that in many ways. Cognition, sensing, and memory play the key roles in this process. Both long term memory and short term memory shape the conditions of information processing rendered via implicit long term memory and explicit long term memory. Implicit long term memory is used unconsciously and can affect thoughts and behaviours. Implicit long term memory performs "implicit learning", a form of learning that occurs without the individual's awareness. It evolves from continuous exposure to events and stimuli and relies on different brain systems that are consciously controlled or 'explicit' learning (Curran and Schacter, 2001).

Could business organizations develop an ability to learn implicitly and derive creative strategies form this implicit learning?

One could hypothesize that the potential for an impact is there and that the key to that is implicit learning. In very much the same way that the human brain resorts to implicit learning to enhance cognitive competencies, executives and corporations could resort to implicit learning to enhance the scope, depth and reach of strategic thinking. And in very much the same way that human brain enhancement of cognitive capacities comes through the growing of new neurons, executives and corporations could enhance their strategic thinking potential by enhancing their organizations implicit memory. Implicit organization memory could be enhanced by greater exposure to silent signals and stimuli originating from beyond the organizations immediate periphery.

\section{References}

1. Arena, D.; Tsolakis, A. C.; Zikos, S.; Krinidis, S.; Ziogou, C.; Ioannidis, D.; Voutetakis, S.; Tzovaras, D. and Kiritsis, D. (2018), "Human resource optimisation through semantically enriched data", International Journal of Production Research, Vol. 56, No. 8, pp. 2855 - 2877. https://doi.org/10.1080/00207543.2017.1415468

International Journal of Management and Applied Research, 2020, Vol. 7, No. 1 
2. Aziz, S. and Chang, S. H. (2018), "Smart-fabric sensor composed of single-walled carbon nanotubes containing binary polymer composites for health monitoring", Composites Science and Technology, Vol. 163, pp. 1-9. https://doi.org/10.1016/j.compscitech.2018.05.012

3. Berghel, H. (2018), "Malice Domestic: The Cambridge Analytica Dystopia", Computer, Vol. 51, pp. 84-89. https://doi.org/10.1109/MC.2018.2381135

4. Burmann, C.; Riley, N. M., Halaszovich, T. and Schade, M. (2017), "The Foundations of Identity-Based Brand Management", In: Burmann, C.; Riley, N.; Halaszovich, T. and Schade, M. (Eds), Identity-Based Brand Management, Wiesbaden: Springer Gabler, pp 1-16.https://doi.org/10.1007/978-3-658-135614_1

5. Brodie, R. J.; Benson-Rea, M. and Medlin, C. J. (2017), "Branding as a dynamic capability: Strategic advantage from integrating meanings with identification", Marketing Theory, Vol. 17, No. 2, pp. 183-199. https://doi.org/10.1177/1470593116679871

6. Castro, V. and Giraldi, J. (2018), "Shared brands and sustainable competitive advantage in the Brazilian wine sector", International Journal of Wine Business Research, Vol. 30 No. 2, pp. 243-259. https://doi.org/10.1108/IJWBR-04-20170019

7. Curran T. and Schacter, D.L. (2001), "Implicit Learning and Memory: Psychological and Neural Aspects", in: Smelser, N. J. and Baltes, P. B. (Eds.), International Encyclopedia of the Social \& Behavioral Sciences, USA: Pergamon, Pages 7237-7241. https://doi.org/10.1016/B0-08-043076-7/03513-0

8. Gross, R. (2014), Themes, Issues and Debates in Psychology, $4^{\text {th }}$ Ed., UK: Hodder Education.

9. Heilmann, P.; Forsten-Astikainen, R. and Kultalahti, S. (2020), "Agile HRM practices of SMEs", Journal of Small Business Management, https://doi.org/10.1111/jsbm.12483

10. Maasø, A. (2018), "Music Streaming, Festivals, and the Eventization of Music", Popular Music and Society, Vol. 41, No. 2, pp. 154-175. https://doi.org/10.1080/03007766.2016.1231001

11. Muraskin, J., Dodhia, S., Lieberman, G., Garcia, J.O., Verstynen, T., Vettel, J.M., Sherwin, J. and Sajda, P. (2016), "Brain dynamics of post-task resting state are influenced by expertise: Insights from baseball players", Human Brain Mapping, Vol. 37, No. 12, pp. 4454-4471. https://doi.org/10.1002/hbm.23321

12. Pavlik, P.I., Jr. and Anderson, J.R. (2005), "Practice and Forgetting Effects on Vocabulary Memory: An Activation-Based Model of the Spacing Effect",

International Journal of Management and Applied Research, 2020, Vol. 7, No. 1 
Could Business Organizations Simulate the Brain's Implicit Learning Process? And Apply That to Strategic Thinking?

Cognitive Science, Vol. 29, No. 4, pp. 559-586. https://doi.org/10.1207/s15516709cog0000_14

13. Pham, P. (2015), “The Impacts Of Big Data That You May Not Have Heard Of", Forbes [Online] Available from:

https://www.forbes.com/sites/peterpham/2015/08/28/the-impacts-of-big-data-thatyou-may-not-have-heard-of/ [Accessed on 2 February 2020].

14. Reber, A.S. (2001), "Tacit Knowledge, Psychology of", in: Smelser, N. J. and Baltes, P. B. (Eds.), International Encyclopedia of the Social \& Behavioral Sciences, USA: Pergamon, pp. 15431-15435. https://doi.org/10.1016/B0-08043076-7/01492-3

15. Schendan, H.E.; Searl, M.M.; Melrose, R.J. and Stern, C.E. (2003), “An fMRI Study of the Role of the Medial Temporal Lobe in Implicit and Explicit Sequence Learning", Neuron, Vol. 37, No. 6, pp. 1013-1025. https://doi.org/10.1016/S08966273(03)00123-5

16. Stangor, C. and Walinga, J. (2014), Introduction to Psychology, Canada: BC Campus.

17. Winter, B.; Perlman, M. and Majid A. (2018), "Vision dominates in perceptual language: English sensory vocabulary is optimized for usage", Cognition, Vol. 179, pp. 213-220. https://doi.org/10.1016/j.cognition.2018.05.008

18. Ullman, M. (2004), "Contributions of memory circuits to language: the declarative/procedural model", Cognition, Vol. 92, No. 1-2, pp. 231-270. https://doi.org/10.1016/j.cognition.2003.10.008

19. Venturini, T. and Rogers, R. (2019) “API-Based Research" or How can Digital Sociology and Journalism Studies Learn from the Facebook and Cambridge Analytica Data Breach, Digital Journalism, Vol. 7, Vol. 4, pp. 532-540, https://doi.org/10.1080/21670811.2019.1591927

20. Viksnins, R. (2004), "Philips Nike Review", CNET [Online] Available from: https://www.cnet.com/reviews/philips-nike-mp3-max-review/ [Accessed on 2 February 2020].

21. Xie, T.T.; Wang, T.Z.; Wei, Y.P. and Ye, E.C. (2019), "Declarative memory affects procedural memory: The role of semantic association and sequence matching", Psychology of Sport and Exercise, Vol. 43, pp. 253-260. https://doi.org/10.1016/j.psychsport.2019.03.009

22. Yang, Y. T. and Kels, C. G. (2016), "Does the Shoe Fit? Ethical, Legal, and Policy Considerations of Global Positioning System Shoes for Individuals with Alzheimer's Disease", Journal of the American Geriatrics Society, Vol. 64, No. 8, pp. 1708- 1715. https://doi.org/10.1111/jgs.14265

International Journal of Management and Applied Research, 2020, Vol. 7, No. 1 